\title{
Clinicopathological Characteristics of Ovarian Sclerosing Stromal Tumor with an Emphasis on TFE3 Overexpression
}

\author{
CHEOL KEUN PARK ${ }^{1,2}$ and HYUN-SOO KIM ${ }^{1}$ \\ ${ }^{1}$ Department of Pathology, Severance Hospital, Yonsei University College of Medicine, Seoul, Republic of Korea; \\ ${ }^{2}$ Department of Pathology, Armed Forces Capital Hospital, Seongnam, Republic of Korea
}

\begin{abstract}
A sclerosing stromal tumor is a very rare benign sex cord-stromal tumor of the ovary. Because its clinical presentation and imaging findings are similar to those of borderline or malignant epithelial tumors and other sex cordstromal tumors, accurate preoperative clinical diagnosis can be difficult. The aim of this study was to analyze the clinicopathological characteristics of SSTs and examine the immunohistochemical expression TFE3, which has not been studied in SSTs. Our study cohort consisted of 9 patients diagnosed as having SST; the median age was 36 years. Radiologically, SSTs presented as multiseptated cystic masses, mixed echoic masses, pseudolobular masses, solid pelvic masses, or uterine subserosal nodules. In 4 of the 9 cases, the preoperative clinical impression was a borderline or malignant ovarian tumor. SSTs displayed the following histopathological features: 1) relatively well-circumscribed cellular nodules that were randomly distributed in the fibrous or edematous stroma; 2) a characteristic alternating pattern of hypercellular and hypocellular areas; 3) a hemangiopericytoma-like vascular growth pattern in the cellular nodules; 4) bland-looking spindle-shaped cells and round or polygonal cells densely clustered around blood vessels; and 5) red blood cell-containing intracytoplasmic vacuole-like spaces in the tumor cell cytoplasm, possibly indicating epithelioid hemangioendothelioma. Immunohistochemically, the tumor cells exhibited diffuse and moderate-to-strong TFE3 expression in 7 of the 9 SSTs. TFE3 was strongly expressed in the nuclei of round or polygonal cells and lutein cells. In contrast, neither luteinized thecomas nor fibromas appreciably expressed TFE3. In summary, our study describes characteristic histopathological
\end{abstract}

Correspondence to: Hyun-Soo Kim, Department of Pathology, Severance Hospital, Yonsei University College of Medicine, 50-1, Yonsei-ro, Seodaemun-gu, Seoul 03722, Republic of Korea. Tel: +82 222281794, +82 23620860, e-mail: hyunsookim@yuhs.ac

Key Words: Ovary, sclerosing stromal tumor, TFE3, immunohistochemistry. features that may be useful for differentiating SSTs from other sex-cord stromal tumors and demonstrates for the first time that SSTs show strong TFE3 expression. Further investigations are necessary to clarify the role of TFE3 in the development of SSTs.

A sclerosing stromal tumor (SST) of the ovary is a rare subtype of an ovarian sex cord-stromal tumor. Approximately 150 ovarian SSTs have been documented in the literature to date (1-7), most of which occurred in patients in their second or third decade of life (2). The clinical presentation of a SST varies, but usually includes menstrual irregularities, pelvic pain, and palpable abdominal masses, as do borderline or malignant ovarian tumors and other ovarian sex cord-stromal tumors. Moreover, the imaging findings for SSTs can resemble those of borderline or malignant ovarian tumors. Hence, SSTs cannot be suspected solely based on symptoms or signs and pose a diagnostic challenge. Histopathologically, SSTs have a pseudolobular architecture, consisting of cellular and vascularized areas in the edematous or fibrous stroma $(6,8)$. The vascularized areas also cause diagnostic difficulty in distinguishing SSTs from vascular tumors.

Transcription factor binding to immunoglobulin $\mathrm{M}$ heavy chain enhancer 3 (TFE3) is a member of the microphthalmia (MiT) family of transcription factors, which includes MiTF, TFEB, TFEC, and TFE3, all of which contain a helix-loophelix leucine zipper dimerization motif, a transactivation domain, and a basic region involved in DNA binding $(9,10)$. Although TFE3 is ubiquitously expressed in humans, it is usually not detected via routine immunohistochemical methods. Research on TFE3 expression in gynecological neoplasms is scarce; consequently, the usefulness of the TFE3 in the diagnosis of gynecological neoplasms remains to be determined. In our recent examination of several SST cases, we observed TFE3 immunostaining in most of the cases. Based on this observation, in this study, we investigated immunohistochemical TFE3 expression in additional SSTs. We also examined the clinical and 
Table I. Clinical features of ovarian sclerosing stromal tumors.

\begin{tabular}{|c|c|c|c|c|c|c|c|c|c|c|}
\hline Case & $\begin{array}{c}\text { Age } \\
\text { (years) }\end{array}$ & Symptom & Imaging finding & $\begin{array}{c}\text { CA 19-9 } \\
(\mathrm{U} / \mathrm{ml})\end{array}$ & $\begin{array}{l}\text { CA } 125 \\
(\mathrm{U} / \mathrm{m})\end{array}$ & Clinical impression & $\begin{array}{l}\text { Associated } \\
\text { disease }\end{array}$ & Management & $\begin{array}{c}\text { Outcome } \\
\text { period }\end{array}$ & Follow-up \\
\hline 1 & 36 & Absent & Mixed echoic mass & 7.2 & 15.9 & $\begin{array}{l}\text { Ovarian borderline tumor } \\
\text { or tubo-ovarian abscess }\end{array}$ & Absent & USO & NED & 7 months \\
\hline 2 & 25 & $\begin{array}{c}\text { Irregular } \\
\text { menstruation }\end{array}$ & Mixed echoic mass & 0.2 & 31.4 & Ovarian cancer & Absent & USO & NED & 53 months \\
\hline 3 & 22 & Amenorrhea & Solid pelvic mass & 1.2 & 12.0 & Ovarian fibrosarcoma & Absent & USO & NED & 28 months \\
\hline 4 & 42 & $\begin{array}{c}\text { Irregular } \\
\text { menstruation }\end{array}$ & Pseudolobular mass & 6.5 & $<0.4$ & Ovarian SST & Absent & USO & NED & 51 months \\
\hline 5 & 52 & Absent & $\begin{array}{l}\text { Pseudolobular mass } \\
\text { with 'spoke-wheel' } \\
\text { appearance }\end{array}$ & NA & 7.6 & Ovarian SST & Adenomyosis & $\mathrm{TH}+\mathrm{BSO}$ & NED & 33 months \\
\hline 6 & 59 & $\begin{array}{c}\text { Vaginal } \\
\text { bleeding }\end{array}$ & $\begin{array}{c}\text { Multiseptated cystic } \\
\text { mass }\end{array}$ & 6.5 & 8.6 & $\begin{array}{l}\text { Ovarian benign tumor } \\
\text { or hydrosalpinx }\end{array}$ & $\begin{array}{l}\text { Endometrial } \\
\text { cancer }\end{array}$ & $\mathrm{TH}+\mathrm{BSO}$ & NED & 31 months \\
\hline 7 & 36 & Absent & $\begin{array}{l}\text { Uterine subserosal } \\
\text { nodule }\end{array}$ & NA & NA & Uterine leiomyoma & PID & UO & NED & 40 months \\
\hline 8 & 40 & Absent & $\begin{array}{l}\text { Multiseptated cystic } \\
\text { mass }\end{array}$ & 0.7 & 131.2 & $\begin{array}{c}\text { Ovarian cancer } \\
\text { or borderline tumor }\end{array}$ & Absent & $\mathrm{TH}+\mathrm{USO}$ & NED & 18 months \\
\hline 9 & 36 & $\begin{array}{l}\text { Abdominal } \\
\text { pain }\end{array}$ & $\begin{array}{c}\text { Multiseptated cystic } \\
\text { mass }\end{array}$ & NA & 32.0 & Uterine leiomyoma & Absent & USO & NED & 18 months \\
\hline
\end{tabular}

CA 19-9: Cancer antigen 19-9; CA 125: cancer antigen 125; NA: not applicable; NED: no evidence of disease; SST: sclerosing stromal tumor; TH: total hysterectomy; UO: unilateral, oophorectomy; USO: unilateral salpingo-oophorectomy.

pathological characteristics of SSTs diagnosed at a single institution. Our findings identify distinctive histopathological and immunohistochemical features of SSTs and expand our knowledge of their clinicopathological features and immunophenotype.

\section{Materials and Methods}

Patients and tissue specimens. The cases were selected from the computerized files of Severance Hospital. A thorough search was performed using the key words "ovary", "sclerosing", "stromal tumor", and "sclerosing stromal tumor". Nine SST cases were identified, all from 2008 to 2015 . As controls, 8 cases of luteinized thecoma and 12 cases of fibroma were used. Clinical and pathological information was obtained from electrical medical information systems and pathology reports. The clinical details that were reviewed included age at the time of diagnosis, clinical presentation, imaging findings, serum tumor marker (CA19-9 and CA 125) levels at the time of admission, preoperative clinical impression, associated medical and/or gynecological disease, management, follow-up period, and current status. The pathological characteristics that were collected included gross appearance, tumor size, circumscribed nodules, alternating pattern of hypercellular and hypocellular areas, hemangiopericytoma-like vascular pattern, red blood cell-containing intracytoplasmic vacuoles, lutein cells, histopathological abnormalities of the stroma such as cystic degeneration, edema, or the presence of myxoid tissue; mitotic counts per 10 high power fields, atypical mitotic figures, and coagulative tumor cell necrosis. This study was reviewed and approved by the Institutional Review Board at Severance Hospital (2017-1205-001).
At the time of diagnosis, specimens were fixed in $10 \%$ neutralbuffered formalin and embedded in paraffin blocks. Fourmicrometer sections were cut from each formalin-fixed, paraffinembedded (FFPE) block and stained with hematoxylin and eosin or prepared for immunohistochemical staining. All available slides were examined via routine light microscopy by two independent pathologists. On microscopic examination, various pathologic factors including the tumor border, cellularity, and architecture, the type and proportion of tumor cells, cytologic atypia, coagulative tumor cell necrosis and abnormal stroma were reviewed.

Histopathological examination. Resected specimens were fixed in $10 \%$ neutral-buffered formalin and embedded in paraffin blocks. From each FFPE block, 4- $\mu$ m sections were cut and stained with hematoxylin and eosin, and the most representative slide containing an appropriate amount of tumor was chosen for immunohistochemical staining.

Immunohistochemistry. Immunohistochemical staining for TFE3 was performed in 9 SSTs, 8 luteinized thecomas, and 12 fibromas. Immunohistochemical staining for inhibin- $\alpha$ and CD31 was performed in 9 SSTs. FFPE sections were deparaffinized and rehydrated in a xylene and alcohol solution. Immunohistochemical staining was performed using a Ventana Benchmark XT automated staining system (Ventana Medical Systems, Tucson, AZ, USA) or a Dako Omnis system (Dako, Agilent Technologies, Carpinteria, CA, USA) according to the manufacturer's recommendations (11-15). Antigen retrieval was performed using Cell Conditioning Solution (CC1; Ventana Medical Systems) or EnVision FLEX Target Retrieval Solution, High pH (Dako, Agilent Technologies, Carpinteria, CA, USA). Sections were incubated with primary antibodies against inhibin- $\alpha$ (dilution 1:50; clone R1; Bio-Rad 
Table II. Pathologic features of ovarian sclerosing stromal tumors.

\begin{tabular}{|c|c|c|c|c|c|c|c|c|c|c|c|c|c|}
\hline Case & $\begin{array}{c}\text { Gross } \\
\text { finding }\end{array}$ & $\begin{array}{l}\text { Tumor } \\
\text { size } \\
(\mathrm{cm})\end{array}$ & $\begin{array}{l}\text { Circum- } \\
\text { scribed } \\
\text { nodule }\end{array}$ & $\begin{array}{c}\text { Alternating } \\
\text { hyper- and } \\
\text { hypocellular } \\
\text { areas }\end{array}$ & $\begin{array}{c}\text { HP-like } \\
\text { vasculature } \\
\text { vacuole }\end{array}$ & $\begin{array}{l}\text { RBC- } \\
\text { containing } \\
\text { intracyto- } \\
\text { plasmic }\end{array}$ & $\begin{array}{l}\text { Lutein } \\
\text { cells }\end{array}$ & $\begin{array}{c}\text { Cystic } \\
\text { degeneration }\end{array}$ & $\begin{array}{l}\text { Myxoid } \\
\text { change }\end{array}$ & Edema & $\begin{array}{c}\text { Mitotic } \\
\text { count } \\
\text { (per } 10 \\
\text { HPFs) }\end{array}$ & $\begin{array}{l}\text { Atypical } \\
\text { mitotic } \\
\text { figure }\end{array}$ & CTCN \\
\hline 1 & $\begin{array}{l}\text { Solid and } \\
\text { cystic }\end{array}$ & 6.5 & Present & Present & Present & Present & Present & Absent & Present & Present & 2 & Absent & Absent \\
\hline 2 & Solid & 6.0 & Present & Present & Present & Present & Present & Absent & Absent & Present & 1 & Absent & Absent \\
\hline 3 & $\begin{array}{l}\text { Solid and } \\
\text { cystic }\end{array}$ & 10.0 & Present & Present & Present & Absent & Present & Absent & Absent & Absent & 3 & Absent & Absent \\
\hline 4 & Solid & 3.4 & Present & Present & Present & Present & Present & Present & Present & Present & 2 & Absent & Absent \\
\hline 5 & Cystic & 5.0 & Present & Present & Present & Present & Present & Absent & Present & Present & 0 & Absent & Absent \\
\hline 6 & Solid & 3.6 & Present & Present & Present & Absent & Present & Absent & Absent & Absent & 1 & Absent & Absent \\
\hline 7 & Solid & 9.0 & Present & Present & Present & Absent & Present & Absent & Absent & Present & 0 & Absent & Absent \\
\hline 8 & $\begin{array}{l}\text { Solid and } \\
\text { cystic }\end{array}$ & 16.0 & Present & Present & Present & Present & Present & Present & Present & Present & 2 & Absent & Absent \\
\hline 9 & $\begin{array}{l}\text { Solid and } \\
\text { cystic }\end{array}$ & 15.0 & Present & Present & Present & Present & Present & Absent & Absent & Present & 3 & Absent & Absent \\
\hline
\end{tabular}

CTCN: Coagulative tumor cell necrosis; HPFs: high power fields; HP-like: hemangiopericytoma-like; RBC: red blood cell.

Laboratories, Inc., Hercules, CA, USA), CD31 (dilution 1:100; clone JC70A; Dako, Agilent Technologies), or TFE3 (dilution 1:100; clone MRQ-37; Cell Marque, Rocklin, CA, USA). After chromogenic visualization using an ultraView Universal DAB Detection Kit (Ventana Medical Systems) or an EnVision FLEX /HRP Kit (Dako, Agilent Technologies, Carpinteria, CA, USA), the slides were counterstained with hematoxylin. Appropriate positive and negative controls were concurrently stained to validate the staining method.

\section{Results}

Clinical features. Table I summarizes the clinical and imaging features of the 9 patients diagnosed with an SST. The age of the patients ranged from 22 to 59 years; the mean and median ages were 38.7 years and 36 years, respectively. Symptoms included irregular menstruation (2 patients), amenorrhea (1 patient), vaginal bleeding (1 patient), and abdominal pain (1 patient); 4 patients had no symptoms. The findings of preoperative imaging studies including ultrasonography and magnetic resonance imaging (MRI) were variable. A multiseptated cystic adnexal mass, a mixed echoic adnexal mass, a pseudolobular adnexal mass, a solid pelvic mass, and a uterine subserosal nodule were observed in 3,2,2,1, and 1 case, respectively. Serum levels of tumor markers were measured before surgery: cancer antigen (CA) 19-9 levels were within the normal range in all 6 patients who underwent the test, and the CA 125 level $(131.2 \mathrm{U} / \mathrm{mL})$ was above the normal range in 1 of the 8 patients who underwent the test.

Only 2 of 9 patients had a clinical impression of a SST before surgery. Four patients had a pre-surgery clinical impression of a borderline or malignant ovarian tumor, and 2 patients were diagnosed with uterine leiomyoma. All patients underwent surgery. Six patients underwent unilateral oophorectomy or salpingo-oophorectomy, 2 patients underwent total hysterectomy with bilateral salpingooophorectomy, and 1 patient underwent total hysterectomy with unilateral salpingo-oophorectomy. The median followup time was 31 months. There was no evidence of recurrence during the follow-up period.

Pathological features. Table II summarizes the pathological features of the 9 patients diagnosed with an SST. All lesions developed in a unilateral ovary. The mean size of the lesions was $8.3 \mathrm{~cm}$ (range=3.4-16.0 cm). Grossly, SSTs showed diverse morphologies. The cut surface of the lesions was solid in 5 cases, solid and cystic in 3 cases, and cystic in 1 case. Relatively well-circumscribed nodules were microscopically observed in all lesions (Figure 1A). The nodules had relatively high cellularity and were surrounded by collagenous stroma and edematous stroma; i.e., alternating hypocellular and hypercellular areas were observed (Figure 1B). The nodules contained thin-walled blood vessels with a dilated, branching, or hemangiopericytoma-like pattern (Figure 1C). Bland-looking spindle-shaped cells and round or polygonal cells encircled the blood vessels in various ratios (Figure 1D); lutein cells with abundant eosinophilic or vacuolated cytoplasm were also present (Figure 1E). Edema was often observed in the hypocellular areas (Figure 1F). Cystic degeneration occurred in 2 cases and myxoid change was present in 4 cases. Intracytoplasmic vacuole-like spaces containing red blood 

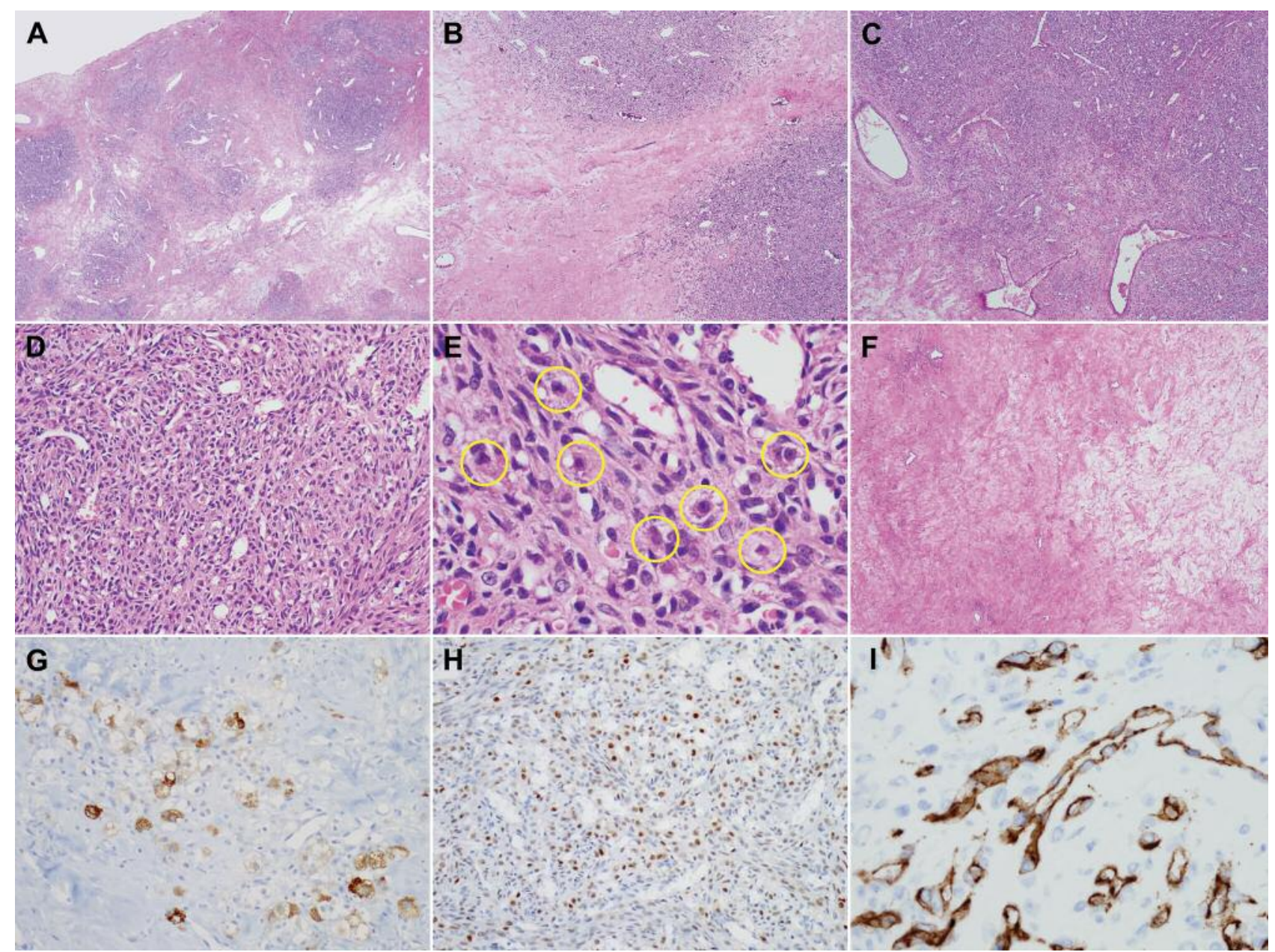

Figure 1. Histopathological and immunohistochemical findings for ovarian sclerosing stromal tumors. A: At scanning power, the tumor consists of several relatively well-circumscribed nodules that are randomly embedded in the edematous or fibrous stroma, resulting in a pseudolobulated appearance. B: At low power, two hypercellular nodules (upper one-third and right lower corner, respectively) are separated by fibrous stroma. C: Variable-sized, irregular-shaped blood vessels are located within and adjacent to the hypercellular nodules and exhibit a staghorn-branching (hemangiopericytoma-like) vascular pattern. D: At medium power, the tumor tissue consists mainly of 2 cellular components: bland-looking, round, or polygonal cells and spindle-shaped cells. E: Several lutein cells (yellow circles) possess abundant eosinophilic or granular cytoplasm and small nuclei. Neither moderate-to-severe cytologic atypia nor atypical mitotic figures were identified. F: The hypocellular areas show fibrous stroma, that often undergoes hyaline degeneration, edema, and myxoid changes. G: The lutein cells display cytoplasmic inhibin- $\alpha$ immunoreactivity. H: TFE3 is localized within the nuclei of round or polygonal cells. I: CD31 immunostaining highlights the vascular endothelial cells. Original magnification: $A, \times 12.5, B-C, \times 40 ; D, \times 100 ; E, \times 200, F, \times 40, G-H, \times 100, I, \times 200$.

cells (RBCs) were found in the tumor cell cytoplasm in 6 cases, suggesting epithelioid hemangioendothelioma. Tumor cells resembling signet-ring cells due to intracytoplasmic vacuolation were observed in 1 case. Mitotic counts were less than 4 per high power fields in all cases. There was no moderate or severe cytologic atypia, abnormal mitotic figures, or coagulative tumor cell necrosis in any of the cases.
Immunohistochemical findings. We performed immunohistochemical staining for inhibin- $\alpha$, CD31, and TFE3. In all 9 SST cases examined, moderate-to-strong inhibin- $\alpha$ immunoreactivity was observed in the lutein cells. The number of lutein cells varied among the cases, and the density of the lutein cells was heterogeneous depending on the tumor location. All 9 SST cases showed diffuse, strong CD31 expression in the vascular endothelial cells. CD31 was clearly 


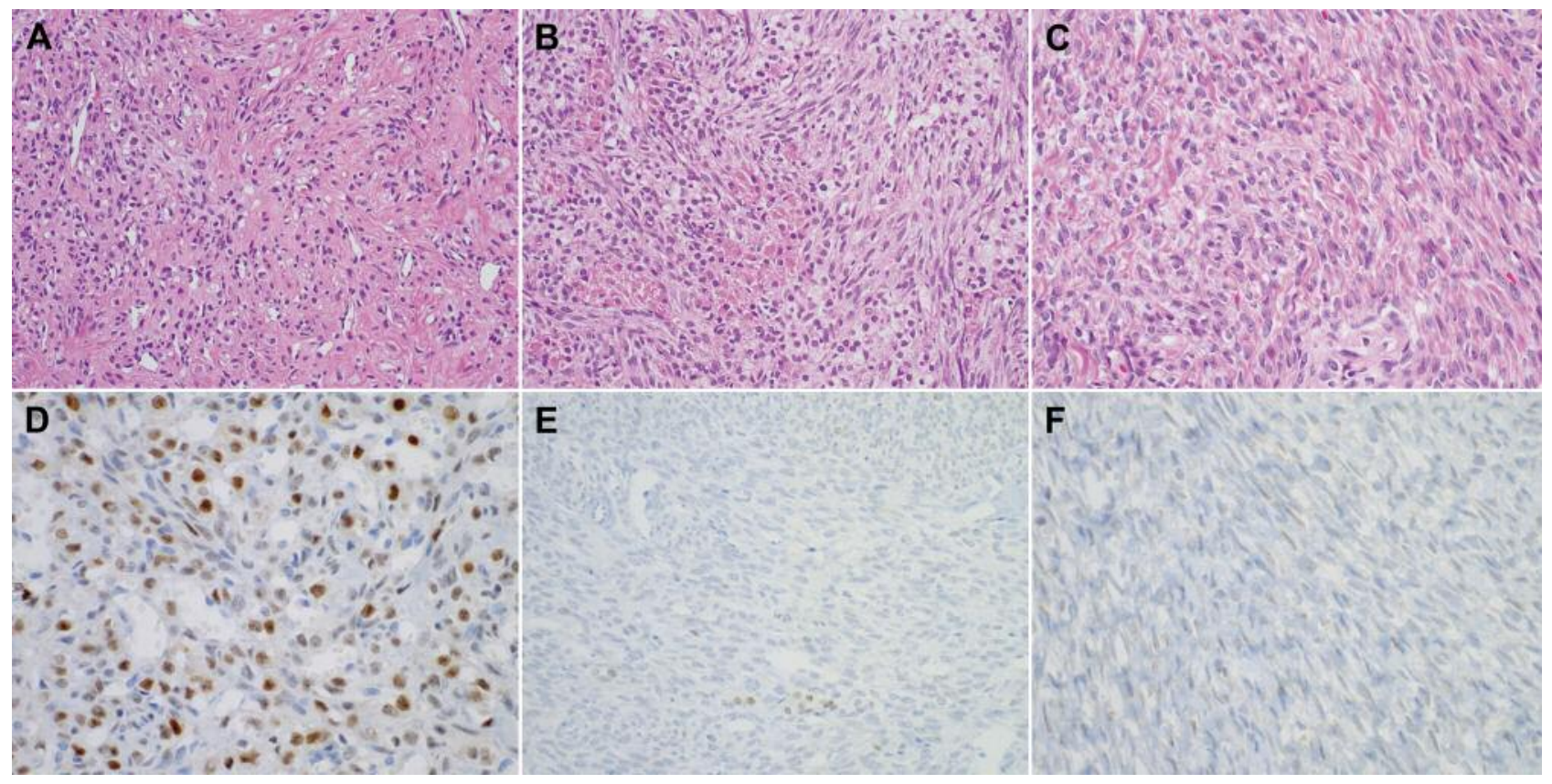

Figure 2. Difference in TFE3 expression among A: ovarian sclerosing stromal tumor, B: luteinized thecoma, and C: conventional fibroma. D: The ovarian sclerosing stromal tumor shows strong nuclear TFE3 immunoreactivity. E: A few lutein cells of in the luteinized thecoma display faint TFE3 expression. F: Conventional fibroma cells do not express TFE3. Original magnification: A-C, ×100; D, ×200; E-F, ×100.

visible in well-vascularized, hypercellular areas, with lower abundance in hypocellular areas with less vascularization. This observation correlated with the histopathological features.

Representative photomicrographs of TFE immunostaining are shown in Figure 2. TFE3 expression was nuclear, diffuse, and moderate-to-strong in 7 of the 9 cases $(77.8 \%)$ of SSTs, and patchy and mild in the remaining 2 cases $(22.2 \%)$. TFE3 was strongly expressed in the round or polygonal cells and lutein cells, and weakly or moderately expressed in most spindle cells and vascular endothelial cells. In contrast, TFE3 was not appreciably expressed in any of the luteinized ovarian thecomas $(0 / 8 ; 0.0 \%)$ or fibromas $(0 / 12 ; 0.0 \%)$ examined, even though a small number (less than 10) of the lutein cells in a few luteinized thecomas displayed faint nuclear TFE3 immunoreactivity.

\section{Discussion}

An SST is a very rare benign tumor of the ovary. It develops in women aged 5 to 51 years, although mainly in young women $(6,16)$. In this study, the median age of the 9 patients with a SST was 36 years (range=22-59 years), and SSTs were also common in reproductive women in their 30's and 40's, as well as postmenopausal women. The most common symptom of an SST is menstrual irregularity. Steroid hormone-related symptoms indicate the possibility of steroid hormone release from the SST in some patients (4). Symptoms may differ from those observed in this study and, in some instances, may include only an increase in serum tumor marker levels.

On ultrasonography, an SST presents as a mass with solid and cystic components that have irregularly thickened septa and heterogeneous echogenicity. On MRI, it presents as a large mass with hyperintense cystic components, and on T2weighted MRI, as a heterogeneous solid mass with intermediate to high signal intensity (17-19). However, owing to similar radiological appearance, it is difficult to differentiate SSTs from other ovarian malignancies based on imaging findings alone (19). Even though early peripheral enhancement of SSTs on contrast-enhanced computed tomography images is thought to be more informative than are data derived from other imaging modalities $(17,18)$, in this study, differentiation of SSTs with the aforementioned imaging features from more common benign, borderline, or malignant ovarian neoplasms was difficult.

Histopathologically, SSTs are sharply circumscribed and heterogeneous. They are characterized by the proliferation of dilated, branching thin-walled blood vessels in a hemangiopericytoma-like vascular pattern, the pseudolobulated appearance of cellular areas, and the presence of hypocellular, myxoid areas $(6,8)$. In the cellular areas, spindle-shaped cells, 
and round or polygonal luteinized cells predominate. Lutein cells containing abundant, eosinophilic or granular cytoplasm are also frequently seen, with edema, myxoid change, and patchy microcalcifications in the hypocellular areas (6). In our study, RBC-containing intracytoplasmic vacuoles were observed in 5 cases, and in 1 case, cells with a signet-ring cell like morphology due to intracytoplasmic vacuolation was observed in the cellular areas. The possibility of an angiosarcoma or epithelioid hemangioendothelioma (EHE) must be considered when these histopathological features are observed. The morphology of angiosarcoma ranges from vasoformative arborizing to solid. Severe cytologic atypia, brisk mitotic activity, and a high proliferative index are the characteristics of angiosarcomas that distinguish them from SSTs (20). EHEs are malignant vascular neoplasms with generally indolent clinical behavior and have also been reported in the para-ovarian region (21). The RBC-containing vacuoles and signet-ring cell-like features of the SST can cause confusion in diagnosis. YAP-TFE3 fusion EHE, a recently reported subtype of EHE, and the SSTs examined in this study have a similar TFE3 expression pattern. However, EHE of the ovary is very rare. Unlike SSTs, YAP-TFE3 fusion EHEs have blood vessels composed of cells with voluminous eosinophilic cytoplasm and exhibit mild-to-moderate cytologic atypia (22, $23)$. The presence of inhibin- $\alpha$-positive lutein cells in cellular areas is highly indicative of an SST.

Owing to their rarity, the origin and pathogenesis of SSTs are still not clear. Based on electron microscopy findings, one hypothesis suggests that SSTs originate from immature stromal cells (24), whereas another suggests that SSTs originate from the muscle-specific actin-positive elements of the theca externa. The formation of the characteristic vasculature of SSTs may involve vascular permeability factor/vascular endothelial growth factor (VPF/VEGF): a previous study reported an increased expression of VPF/VEGF in SSTs, as determined via reverse transcription polymerase chain reaction and immunohistochemistry (25). Chromosome 12 trisomy and chromosome 16 monosomy in SSTs have also been reported $(25,26)$.

This study is the first to show overexpression of TFE3 in SSTs. The mechanism underlying TEF3 expression in SSTs is unknown. A previous study reported reduced VEGF expression following siRNA-mediated knockdown of TFE3 in retinal pigmented epithelium (27), which implicates TFE3 in VEGF expression. By stimulating VEGF expression, TFE3 may be responsible for the characteristic vascular proliferation observed in SSTs. Further investigation of the associations among TFE3 expression, VEGF expression, and vascular proliferation is necessary.

SSTs should be distinguished from other benign sex cordstromal tumors, including fibromas, thecomas, and microcystic stromal tumors (6). Most benign sex cordstromal tumors are more grossly homogeneous than SSTs.
The alternating pattern of hypercellular and hypocellular areas is not observed in ovarian fibromas or thecomas $(5,6)$. Microcystic stromal tumors may exhibit histopathological features similar to those of SSTs owing to the separation of tumor cells caused by the presence of collagenous stroma or thick hyaline bands. However, microcystic tumors lack lutein cells and the characteristic vasculature of SSTs, while displaying prominent cystic changes.

In summary, an SST is a rare benign sex cord-stromal tumor of the ovary. Because the clinical presentation and imaging features of SSTs vary greatly, it is difficult to differentiate them from borderline or malignant ovarian tumors based on clinical features alone. In this study, the clinical and pathological features of 9 SSTs diagnosed at a single institution were analyzed, and TFE3 overexpression was observed in the SSTs. Our study shows that SSTs are characterized by the presence of cellular and hypocellular areas in an alternating pattern. The proliferation of blandappearing spindle cells and lutein cells and a hemangiopericytoma-like vascular pattern were observed in cellular, pseudolobulated areas, while myxoid stroma was found in hypocellular areas. These histopathological features of SSTs are useful for differentiating them from other benign sex cord-stromal tumors. Further investigation on the mechanism of TEF3 expression in SSTs is needed.

\section{Acknowledgements}

This research was supported by the Basic Science Research Program through the National Research Foundation of Korea (NRF) funded by the Ministry of Education (2016R1D1A1B03935584) and by a faculty research grant from Yonsei University College of Medicine (6-2017-0036).

\section{References}

1 Kim ID, Chang HS and Hwang KJ: Sclerosing stromal cell tumor of the ovary in pregnancy: A case report and review of the literature. Korean J Obstet Gynecol 55: 261-264, 2012.

2 Iravanloo G, Nozarian Z, Sarrafpour B and Motahhary P: Sclerosing stromal tumor of the ovary. Arch Iran Med 11: 561562, 2008.

3 Peng HH, Chang TC and Hsueh S: Sclerosing stromal tumor of ovary. Chang Gung Med J 26: 444-448, 2003.

4 Biswas N, Rout AJ and Omar S: Sclerosing Stromal Tumor of Ovary-A Rare Ovarian Disease Presenting With Hyperandrogenism: A Case Report. International Journal of Scientific Study 2: 133-135, 2015.

5 Akbulut M, Colakoglu N, Soysal ME and Duzcan SE: Sclerosing stromal tumor of the ovary: report of a case and review of the literature. Agean Pathology Journal 1: 84-89, 2004.

6 Roth LM, Gaba AR and Cheng L: On the pathogenesis of sclerosing stromal tumor of the ovary: a neoplasm in transition. Int J Gynecol Pathol 33: 449-462, 2014.

7 Hafez AAE: Sclerosing stromal tumor of the ovary: A rare entity with distinctive features. Case Reports Clin Pathol 1: 5-7, 2014. 
8 Martinelli G, Govoni E, Pileri S, Grigioni FW, Doglioni C and Pelusi G: Sclerosing stromal tumor of the ovary. A hormonal, histochemical and ultrastructural study. Virchows Arch A Pathol Anat Histopathol 402: 155-161, 1983.

9 Haq R and Fisher DE: Biology and clinical relevance of the micropthalmia family of transcription factors in human cancer. J Clin Oncol 29: 3474-3482, 2011.

10 Lin G and Doyle LA: An update on the application of newly described immunohistochemical markers in soft tissue pathology. Arch Pathol Lab Med 139: 106-121, 2015.

11 Do SI, Yoon G, Kim HS, Kim K, Lee H, Do IG, Kim DH, Chae SW and Sohn JH: Increased Brahma-related Gene 1 Expression Predicts Distant Metastasis and Shorter Survival in Patients with Invasive Ductal Carcinoma of the Breast. Anticancer Res 36: 4873-4882, 2016.

12 Jang MI, Sung JY, Kim JY and Kim HS: Clinicopathological Characteristics of Metaplastic Papillary Tumor of the Fallopian Tube. Anticancer Res 37: 3693-3701, 2017.

$13 \mathrm{Kim}$ JY, Na K and Kim HS: Clinicopathological Characteristics of Mitotically-active Cellular Fibroma of the Ovary: A Singleinstitutional Experience. Anticancer Res 37: 2557-2564, 2017.

$14 \mathrm{Na}$ K, Kim EK, Jang W and Kim HS: CTNNB1 Mutations in Ovarian Microcystic Stromal Tumors: Identification of a Novel Deletion Mutation and the Use of Pyrosequencing to Identify Reported Point Mutation. Anticancer Res 37: 3249-3258, 2017.

$15 \mathrm{Na} \mathrm{K}$, Sung JY and Kim HS: Stromal p16 Overexpression in Adult Granulosa Cell Tumors of the Ovary. Anticancer Res 37: 2437-2444, 2017.

16 Chalvardjian A and Scully RE: Sclerosing stromal tumors of the ovary. Cancer 31: 664-670, 1973.

17 Kim JY, Jung K-J, Chung DS, Kim OD, Lee JH and Youn SK: Sclerosing stromal tumor of the ovary: MR-pathologic correlation in three cases. Korean Journal of Radiology 4: 194199, 2003.

18 Jung SE, Rha SE, Lee JM, Park SY, Oh SN, Cho KS, Lee EJ, Byun JY and Hahn ST: CT and MRI findings of sex cordstromal tumor of the ovary. American journal of Roentgenology 185: 207-215, 2005.

19 Joja I, Okuno K, Tsunoda M, Takeda Y, Sugita K, Mizutani Y, Miyagi Y, Kudo T, Notohara K and Hiraki Y: Sclerosing stromal tumor of the ovary: US, MR, and dynamic MR findings. J Comput Assist Tomogr 25: 201-206, 2001.
20 Yaqoob N, Nemenqani D, Khoja H, Hafez M, Tulbah A and AlDayel F: Ovarian angiosarcoma: a case report and review of the literature. J Med Case Rep 8: 47, 2014.

21 Pillay K and Chetty R: Epithelioid hemangioendothelioma of the paraovarian region. Journal of gynecologic surgery 18: 33-36, 2002.

22 Flucke U, Vogels RJ, de Saint Aubain Somerhausen N, Creytens DH, Riedl RG, van Gorp JM, Milne AN, Huysentruyt CJ, Verdijk MA, van Asseldonk MM, Suurmeijer AJ, Bras J, Palmedo G, Groenen PJ and Mentzel T: Epithelioid Hemangioendothelioma: clinicopathologic, immunhistochemical, and molecular genetic analysis of 39 cases. Diagn Pathol 9: 131, 2014.

23 Antonescu CR, Le Loarer F, Mosquera JM, Sboner A, Zhang L, Chen CL, Chen HW, Pathan N, Krausz T, Dickson BC, Weinreb I, Rubin MA, Hameed M and Fletcher CD: Novel YAP1-TFE3 fusion defines a distinct subset of epithelioid hemangioendothelioma. Genes Chromosomes Cancer 52: 775-784, 2013.

24 Lam RM and Geittmann P: Sclerosing stromal tumor of the ovary. A light, electron microscopic and enzyme histochemical study. Int J Gynecol Pathol 7: 280-290, 1988.

25 Kawauchi S, Tsuji T, Kaku T, Kamura T, Nakano $H$ and Tsuneyoshi M: Sclerosing stromal tumor of the ovary: a clinicopathologic, immunohistochemical, ultrastructural, and cytogenetic analysis with special reference to its vasculature. Am J Surg Pathol 22: 83-92, 1998.

26 Lopes JM, Seruca R, Hall AP, Branco P and Castedo SM: Cytogenetic study of a sclerosing stromal tumor of the ovary. Cancer Genet Cytogenet 49: 103-106, 1990.

27 Ford KM and D'Amore PA: Molecular regulation of vascular endothelial growth factor expression in the retinal pigment epithelium. Mol Vis 18: 519-527, 2012.
Received July 31, 2017

Revised August 11, 2017

Accepted August 21, 2017 